\title{
Climate Change Impact on Flow Regimes of Rivers in Bhutan and Possible Consequences for Hydropower Development
}

\author{
Stein Beldring and Astrid Voks $\varnothing$
}

The mentioned report was published by Norwegian Water Resources Directorate. Summary of the Report is extracted from the Report.

\section{SUMMARY}

$\mathbf{T}$ The main objective of this study is to assess the impacts of climate change on the hydrological regime of the rivers, of the Kingdom of Bhutan to provide in information for the country's hydropower development programme. A spatially distributed hydrological model was used for describing hydrological processes including glacier mass balance, snow storage, subsurface water storage and streamflow (river flow). Observed precipitation, temperature and streamflow from the station network of the Department of Energy of the Royal Government of Bhutan, Hydromet Services Division were used for calibrating and running the hydrological model for the period 1991-2008. Results from climate model simulations with two emission scenarios for greenhouse gas concentrations in the atmosphere were used to determine precipitation and temperature time series for the meteorological station sites for the period 1981-2100. These precipitation and temperature time series were used as input to hydrological modelling for the period 1981-2100. Hydrological model results for the water balance and streamflow of 17 catchments in Bhutan and for the entire land surface of Bhutan was considered in this study, with particular emphasis on the control period 1981-2010 and the projection periods 2021-2050 and 2071-2100. The hydrological model simulations are transient, i.e. the hydrological model was run from 1981 until 2100, which results for the control and projection periods were extracted from the transient simulations. The hydrological model has a high precision with regard to simulating streamflow, both with input from observed meteorological data or with input from climate model data.

Increasing concentrations of greenhouse gases in the atmosphere changes the radiation balance of the earth-atmospheresystem, resulting in increasing ground temperatures and changes in cloud cover, precipitation, air humidity, radiation, wind and other meteorological elements. These changes will lead to changes in the land phase of the hydrological cycle with impacts on glacier mass balance, snow storage, soil moisture in the unsaturated zone, groundwater storage, evapotranspiration and runoff.

The change in mean annual temperature from 1981 to 2050 averaged over the area studied in this work is approximately $1.4^{\circ} \mathrm{C}$, while the change in mean annual temperature from 1981 to 2100 is $2.5^{\circ} \mathrm{C}$ and $4.9^{\circ} \mathrm{C}$ for the each of two emission scenarios for greenhouse gases, respectively. The change in mean annual precipitation sums from 1981-2010 to 2021-2050 and 2071-2100 are mostly negative and the changes in precipitation are larger by the end of the century than by the middle. Large negative changes are more frequent in southern parts of Bhutan. Precipitation changes are small for the winter (December, January, February), spring (March, April, May) and autumn (September, October, November) seasons. For the summer season (June, July, August) the changes are negative.

Glacier mass balance is negative for most areas for the period 1981-2100, resulting in decreasing glacier ice volumes and glacier covered areas. Until the middle of the 21st century negative glacier mass balance is not sufficiently large to melt more than small fractions of the glacier covered areas completely, but by the end of the

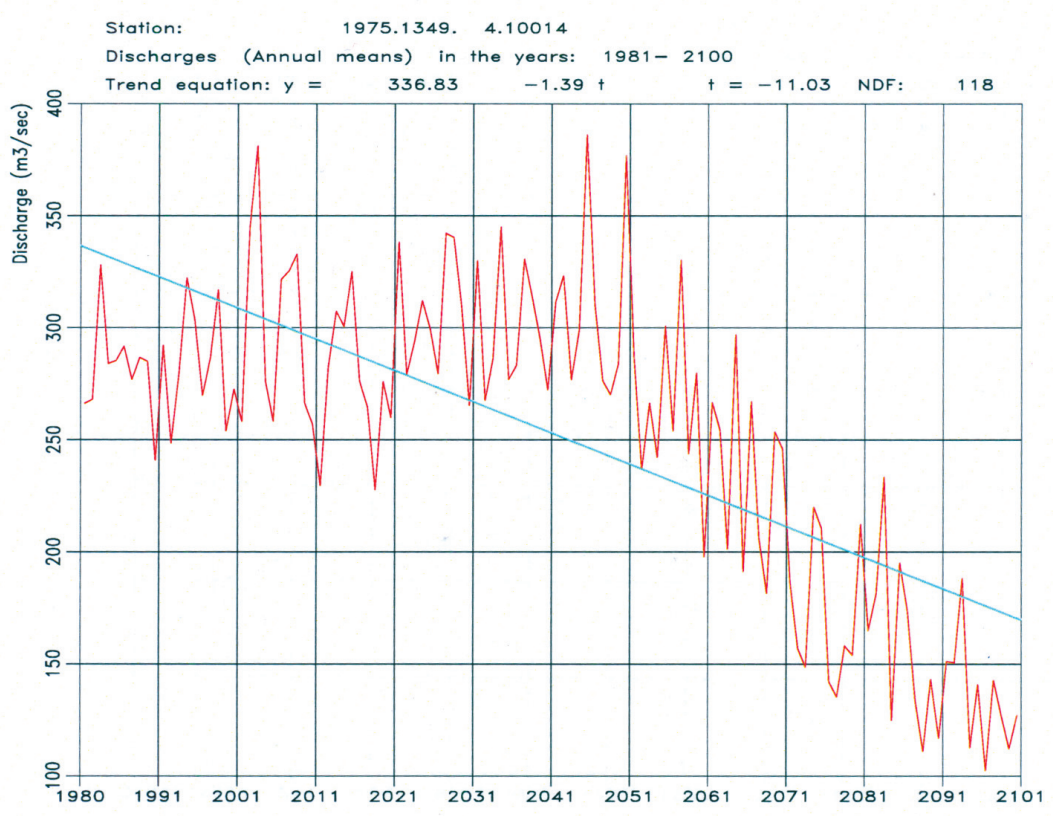

Figure 1. Hydrological model results for annual mean streamflow $\left(\mathrm{m}^{3} / \mathrm{s}\right)$ for period 1981-2100 for catchment 1349 Wangdirapids with precipitation and temperature input from climate projection Echam A2 downscaled to meteorological station sites. Glacier covered areas are treated as time-variant. 
century large areas that are glacier covered at present will be completely devoid of glacier ice. The contribution to streamflow from glacier ice melt water will remain mostly unchanged during the first half of the 21st century, while it will diminish during the second half. For most catchments streamflow is not changing much from 1981-2010 to 2021-2050. However, as a result of smaller precipitation amounts, in particular during summer, there is a reduction in streamflow for catchments with small glacier covered fraction since they will not receive a contribution to runoff from melting ice. The catchments with largest glacier covered fraction will experience increased streamflow caused by increased contribution to runoff from glacier ice melt. For the Period 20712100 there is a decline in precipitation compared to the period 1981-2010. In combination with a reduction in glacier volume and area this leads to a large reduction in streamflow. Catchments with a negligible glacier covered fraction will also experience reduced streamflow, but this is a result of perception change.

Mean annual discharge available for hydropower production has been estimated assuming a run-of- river hydropower plant at the outlet of each catchment with turbines with a capacity for annual inflow in the range $20 \%-200 \%$ of mean annual inflow for the period 19812010. The change in mean annual discharge available for hydropower production from 1981-2010 to 2021-2050 varies between $13 \%$ decrease and $7 \%$ increase for all catchments and both emission scenarios for greenhouse gases. The change in mean annual discharge available for hydropower production from 1981-2010 to 2071-2100 is influenced by reduced contribution to streamflow from glacier ice melt. This leads to a decline in mean annual discharge available for hydropower production compared to the period 1981-2010 varying from $76 \%$ to $-4 \%$ the rate of change depending on the initial ice covered fractions of the catchments. The difference in mean annual discharge available for hydropower production between the two climate projections is now larger. Higher temperature increase for climate projection Echam A2 results in more rapid melting of glacier ice than for climate projection Echam B1 and larger contribution to streamflow as long as the glacier are present, but also to earlier disappearance of glacier ice and consequently reduce streamflow when the glacier covered area is smaller.

The glacier covered areas of the catchments were treated as time-variant with initial ice volumes and glacier covered areas modified by model mass balance. streamflow downstream of areas with glaciers will decline if glacier covered areas and the contribution to run off from melting glacier ice is reduced. Hydrological model simulations with constant glacier covered areas were performed as a sensitivity analysis. They show a strong increase in streamflow and mean annual discharge by the end of the 21st century as a result of increasing temperatures leading to higher glacier ice melt rates. Until the middle of the century there is only a small difference between the two sets of model results, as model simulations with time-variant glacier covered areas have only led to a small reduction of glacier ice volume and area.

The annual cycle of meteorological processes in Bhutan will not change during the 21st century in the sense that the largest amounts of precipitation will still occur during summer and the smallest during winter. At high altitudes temperature will remain below freezing point during the winter and precipitation will accumulate as snow. The annual cycle of streamflow follows the same pattern as in the present climate with low flow during winter and high flow during summer as a result of the combined effect of snowmelt and larger amounts of precipitation in the summer season than in the rest of the year. There is a relatively small change in the magnitude of streamflow until the middle of the 21st century, whereas are larger by the end of the 21st century due to reduced contribution from melting of glacier ice.

Editors: The hydrological projection of Bhutan under climate change scenario will be meaningful to neighboring countries such as Nepal and India. However, due to high rainfall in Bhutan compared to Nepal the consequences to Nepal will be severe than Bhutan. Dr. Luna Bharati, Head IWMI Office-Nepal, et al. in her paper Hydrologic Characterization of the Koshi Basin and the Impact of Climate Change has analyzed the hydrological projection of Koshi River, Nepal under the climate changes scenario with the help of Global and Regional circulation models.

Results from this study show an increase in temperature and reduction in mean annual rainfall for most of the Koshi basin however, instead of looking at annual averages and trends, when environmental components such as frequency of high and low flows were assessed, results showed that there will be an increase in the number of extreme events; i.e., both low flows and large floods. There is however; a large degree of uncertainty related to climate projections (Bharati, Gurung and Jayakody 2012).

\section{References}

Beldrin, Stein and Astrid Vokso, May 2011. Climate Change Impact on Flow Regimes of Rivers in Bhutan and Possible Consequences for Hydropower Development, published by Norwegiam water Resources and Energy Directorate, Oslo, Norway.

Bharati, Luna, Gurung, Pabitra and Jayakody, Priyantha, April 2012. Hydrological Characterisation of Koshi Basin and the Impact of Climate Change, HYDRO Nepal Journal, Special Issue. 